\title{
Facile and scalable preparation of ZIF-67 decorated cotton fibers as recoverable and efficient adsorbents for removal of malachite green
}

Linhua Li ${ }^{1}$, Lin Yang ${ }^{1}$, Rui Zou ${ }^{1}$, Jianwu Lan ${ }^{1,2^{*}}$, Jiaojiao Shang ${ }^{1,2}$, Baojie Dou ${ }^{1}$, Hongyu Liu ${ }^{1}$ and Shaojian Lin ${ }^{1,2^{*}}$

\begin{abstract}
Recently, metal-organic frameworks (MOFs) have received considerable attention as highly efficient adsorbents for dye wastewater remediation. However, the immobilization of MOFs on the substrate surfaces to fabricate easy recyclable adsorbents via a facile route is still a challenge. In this work, ZIF-67/cotton fibers as adsorbents for dye removal were prepared in a large-scale using a simple coordination replication method. The successful fabrication of the ZIF$67 /$ cotton fibers was confirmed by FTIR, XRD, XPS, SEM and BET analysis, respectively. As expected, the as-prepared ZIF-67/cotton fibers exhibited high adsorption capacity of $3787 \mathrm{mg} / \mathrm{g}$ towards malachite green (MG). Meanwhile, the adsorption kinetics and isotherm obeyed the pseudo-second-order kinetics and Langmuir model, respectively. Moreover, its removal efficiency towards MG was not significantly influenced by the $\mathrm{pH}$ and ionic strength of aqueous solution. Most importantly, the ZIF-67/cotton fibers can remove MG from synthetic effluents, and it can be easily regenerated without filtration or centrifugation processes, with the regeneration efficiency remaining over $90 \%$ even after 10 cycles. Additionally, the ZIF-67/cotton fibers presented excellent antimicrobial performance against E. coli and S. aureus. Hence, the distinctive features of the as-prepared ZIF-67/cotton fibers make it promisingly applicable for the colored wastewater treatment.
\end{abstract}

Keywords: ZIF-67, Cotton fibers, Dye removal, Adsorbent, Wastewater remediation

\section{Introduction}

Nowadays, leather industry plays an important role in the world's economy. However, the leather industry wastewater is one of the main pollution factors of the ecological environment [1]. These industrial wastes contain many toxic substances that are harmful to human health and the environment, such as dyes, transition metal ions etc. $[2,3]$. Malachite green (MG) is a typical cationic dye that is widely utilized in the leather-making industry [4]. It is a carcinogenic substance and has been classified as a

\footnotetext{
*Correspondence: lanjw@scu.edu.cn; sjlin@scu.edu.cn

${ }^{1}$ College of Biomass Science and Engineering, Sichuan University,

Chengdu 610065, People's Republic of China

Full list of author information is available at the end of the article
}

recalcitrant dye molecule because of its resistance to degradation caused by light, heat and natural oxidants $[5,6]$. Therefore, it is crucially important to remove the MG pollutant in the aspect of environmental protection and human health. So far, many methods have been proposed for removal of MG from wastewater, such as membrane techniques [7], chemical oxidation [8,9], photocatalytic degradation [10, 11], intensified biological methods [12], Fenton process [13], ion exchange [14] as well as adsorption methods $[15,16]$. Among those methods, adsorption technology is regarded as an economical and efficient method for the removal of dyes from wastewater due to its simple equipment requirements, high efficiency, low energy consumption and easy operation $[17,18]$. Until now, various absorbents, such as graphene [19], activated 
carbon [20] and activated diatomite [21], have been employed to remove MG from wastewater. Nevertheless, such adsorbents were limited by their high cost and unsatisfactory adsorption performances in the practical application [22]. Hence, development of a low cost and effective adsorbent by a simple method is highly desired.

Recently, metal-organic frameworks (MOFs) belonging to a new family of porous crystalline frameworks, derived from metal ions and organic ligands linker, have been viewed as promising adsorbents for dye removal. The reason can be attributed to their prominent advantages such as high surface areas, adjustable compositions, regular porous structures and easy functionalization [23-25]. In recent years, utilization of MOFs as highly efficient adsorbents for removal of MG has been reported by a large number of literatures. For instance, two kinds of metal-organic frameworks (MOFs), MIL-53(Al) and MIL-53(Al)- $\mathrm{NH}_{2}$, were prepared for removal of MG dyes from wastewater [5]. Besides, many zeolitic imidazolate frameworks (ZIFs) or their composites were also used to remove MG, such as ZIF-8 [26], ZIF-8@Fe/Ni [27] and ZIF-67 [28] etc. Noteworthily, among various MOFs, ZIF-67 exhibits significantly high adsorption capacity for MG, the adsorption capacity of ZIF-67 towards MG can above $2000 \mathrm{mg} / \mathrm{g}$ [28]. Moreover, ZIFs shown excellent moisture, chemical and thermal stability compared with other carboxylate linker-based MOFs [29]. Therefore, ZIF-67 seems to be a promising adsorbent to remove MG. However, current ZIF-67 is mostly utilized in powder form. As a result, it is difficult to be separated and recycled in practical applications, potentially resulting in the secondary pollution by such nano-scale materials. Hence, how to fabricate ZIF-67 materials with outstanding recyclability is still a tremendous challenge.

Nowadays, immobilization of the ZIF-67 on a substrate surface is an efficient strategy to endow it with facile recyclable feature. Among various substrates, the cotton fiber has attracted much attention as a promising substrate owing to features of natural abundance, biodegradability and environmental friendliness. Moreover, cotton fiber as bio-polymer, is obtained directly from nature without extra processing. Therefore, a number of the ZIF-67/cotton fiber composites as adsorbents have been successfully developed in different routes. For example, Emam et al. reported that ZIF-67 nanocrystals were formed on the silicate modified cotton fibers [30]. Another example, Jassal's group prepared a ZIF-67/cotton fiber on the carboxymethylated cotton fiber, then resultant composite as an efficient adsorbent was used to adsorb various high concentrations of organic pollutants [31]. However, the above-mentioned methods for fabrication of the ZIF-67/ cotton fiber composites have several limitations, including cumbersome procedure, use of organic solvents and harsh reaction conditions, which ultimately restrict their practical applications. Therefore, it is desire to develop a facile route to prepare the ZIF-67/cotton fiber composites in a large scale for MG removal. Fortunately, Xin's group reported a coordination replication method to facile and eco-friendly anchoring of MOFs on fibrous substrates at room temperature [32], making it possible to prepare MOF-coated composites in a large scale. Based on the above-mentioned results, a coordination replication method could possibly realize preparation of the ZIF-67/cotton fiber composites in a facile procedure. Moreover, to the best of our knowledge, fabrication of MOF composites as adsorbents for removal of dyes via a coordination replication method has not been reported yet. Hence, facile and scalable fabrication of the ZIF-67/ cotton fibers as efficient adsorbents for removal of MG is expected.

Herein, the facile and scalable in-situ growth of ZIF67 nanocrystals on the cotton fibers as adsorbents for removal of MG were developed using an easy coordination replication strategy (Scheme 1). First of all, the successful preparation of the ZIF-67/cotton fibers are characterized by the scanning electron microscope (SEM), X-ray photoelectron spectroscopy (XPS), X-ray diffraction (XRD), Fourier-transform infrared (FTIR)

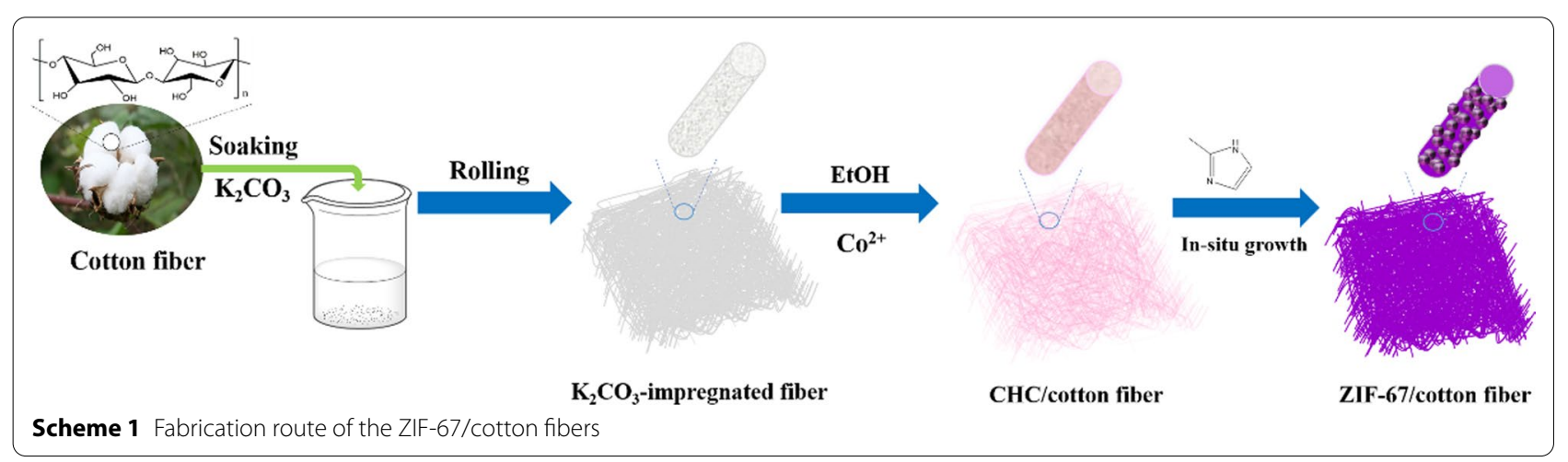


and Brunauer-Emmett-Teller (BET) analysis, respectively. Then, the adsorption capacities of the as-prepared ZIF-67/cotton fibers towards MG are investigated in the both static and dynamic states. Moreover, the adsorption kinetics, adsorption isotherms and adsorption mechanism of the as-synthesized ZIF-67/cotton fibers towards MG are discussed. Additionally, the effects of dye concentration, $\mathrm{pH}$ value and ionic strength on the MG removal of the ZIF-67/cotton fibers are studied in detail. Meanwhile, the adsorption performance of the as-prepared ZIF-67/cotton fibers towards MG in the synthetic effluent is evaluated. Finally, the reusability and antibacterial activity of the ZIF-67/cotton fiber are also investigated.

\section{Experimental section}

\subsection{Materials}

The cotton fibers were provided by Suining Kangda Sanitary Materials Co. Ltd. Cotton fibers were treated with boiling water for $8 \mathrm{~h}$ and ethanol for $30 \mathrm{~min}$ for purification. Potassium carbonate $\left(\mathrm{K}_{2} \mathrm{CO}_{3}, 99 \%\right)$, cobalt chloride $\left(\mathrm{Co}(\mathrm{Cl})_{2} \cdot 6 \mathrm{H}_{2} \mathrm{O}, \mathrm{AR}, 99 \%\right)$, cobalt nitratehexahydrate $\left(\mathrm{Co}\left(\mathrm{NO}_{3}\right)_{2} \cdot 6 \mathrm{H}_{2} \mathrm{O}, \mathrm{AR}, 99 \%\right)$, 2-methylimidazole (2-MIM, 98\%), ethanol $\left(\mathrm{CH}_{3} \mathrm{CH}_{2} \mathrm{OH}, 99.7 \%\right)$, methanol $\left(\mathrm{CH}_{2} \mathrm{OH}, 99 \%\right)$ malachite green (MG, $\left.99 \%\right)$ and sodium chloride $(\mathrm{NaCl}, 99 \%)$ were all purchased from Chengdu Chron Chemicals Co. Ltd. All chemicals were used as received without additional purification.

\subsection{Preparation of ZIF-67/cotton fibers}

Firstly, a cotton fibrous membrane $(10 \mathrm{~cm} \times 10 \mathrm{~cm})$ was immersed into $200 \mathrm{~mL}$ of $20 \mathrm{wt} \% \mathrm{~K}_{2} \mathrm{CO}_{3}$ aqueous solution for $1 \mathrm{~h}$. Then, the treated cotton fibers were dried at $60{ }^{\circ} \mathrm{C}$ for $6 \mathrm{~h}$ to remove excess water. Next, the $\mathrm{K}_{2} \mathrm{CO}_{3}$-coated cotton fibers were immersed in $100 \mathrm{~mL}$ of a $0.3 \mathrm{M} \mathrm{Co}(\mathrm{Cl})_{2} \cdot 6 \mathrm{H}_{2} \mathrm{O}$ ethanol solution for $24 \mathrm{~h}$ to form an insoluble cobalt hydroxy carbonate $(\mathrm{CHC})$ precursor layer, followed by washing with deionized water and dried at room temperature. For the in-situ growth of ZIF67 nanocrystals on the cotton fibers, the $\mathrm{CHC} /$ cotton fibers were immersed in $100 \mathrm{~mL}$ of $0.3 \mathrm{M}$ 2-MIM ethanol solution for $12 \mathrm{~h}$, then washed with ethanol for three times and dried in the vacuum oven at $100{ }^{\circ} \mathrm{C}$ for $12 \mathrm{~h}$. Finally, the ZIF-67/cotton fibers were also synthesized for comparison in the subsequent experiments.

\subsection{Characterization}

The morphologies of the samples were observed using a JSM-7500F field emission scanning electron microscope (SEM) with energy-dispersive X-ray spectroscopy (EDS) analysis, operating at an acceleration voltage of $15.0 \mathrm{kV}$ after gold spraying process. Fourier transform infrared (FTIR) spectroscope was used to investigate the chemical structure of the samples in an attenuated total reflection (ATR) mode, measured by a Bruker Vertex 70 spectrometer at the wavenumber range of $500-$ $4000 \mathrm{~cm}^{-1}$. The X-ray diffraction (XRD) spectroscopies of the samples were measured at room temperature using $\mathrm{Cu}-\mathrm{K} \alpha$ radiation on Philips X'Pert diffractometer.

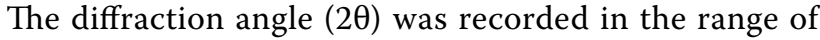
$5^{\circ}-50^{\circ}$. X-ray photoelectron spectroscopy (XPS) was used to test the elemental composition and chemical state of the samples. The specific surface area and the pore size distribution of the samples were determined by the Brunauer-Emmett-Teller (BET) analysis, while the $\mathrm{N}_{2}$ adsorption/desorption isotherms of the cotton fibers and ZIF-67/cotton fibers were measured by the Micromeritics Surface Area and Porosity Analyzer (Gemini VII 2390).

\subsection{MG adsorption experiments}

All adsorption experiments of the ZIF-67/cotton fibers toward MG were performed by batch methods. The adsorption kinetics experiments were carried out by adding $100 \mathrm{mg}$ of ZIF-67/cotton fibers into $200 \mathrm{~mL}$ of MG solution with an initial concentration of $300 \mathrm{mg} / \mathrm{L}$ at room temperature. At predetermined time intervals, the remaining concentration of MG was measured by spectrophotometry at $\lambda_{\max }=618 \mathrm{~nm}$. For adsorption isotherms experiments, $10 \mathrm{mg}$ of the ZIF-67/cotton fibers was added into $20 \mathrm{~mL}$ of MG solutions with different initial concentrations ranging from 100 to $2100 \mathrm{mg} / \mathrm{L}$. The adsorption experiments were performed for $12 \mathrm{~h}$ to ensure that adsorption equilibrium was achieved. The effect of $\mathrm{pH}$ for removal of MG was investigated by adding $10 \mathrm{mg}$ of the ZIF-67/cotton fibers into $20 \mathrm{~mL}$ of MG solution $(100 \mathrm{mg} / \mathrm{L})$ with different $\mathrm{pH}$ values. The $\mathrm{pH}$ of the MG solution was controlled by adding $\mathrm{HCl}$ or $\mathrm{NaOH}$ aqueous solutions. The effect of ionic strength for removal of MG was evaluated under different concentrations of $\mathrm{NaCl}$ aqueous solution ranging from 1 to $6 \mathrm{~mol} / \mathrm{L}$. To evaluate the recyclability of the ZIF-67/ cotton fibers, $100 \mathrm{mg}$ of the ZIF-67/cotton fibers were added into $50 \mathrm{~mL}$ of MG solution with concentration of $20 \mathrm{mg} / \mathrm{L}$. The MG-loaded adsorbent was regenerated by immersing it into ethanol to desorb MG. Then, the regenerated adsorbent was reused to adsorb MG. Herein, the adsorption capacity $\left(Q_{t}\right)$ of the ZIF-67/cotton fibers toward MG was calculated through equation below (1):

$$
Q_{t}=V\left(C_{0}-C_{t}\right) / m
$$

where $C_{0}(\mathrm{mg} / \mathrm{L})$ and $C_{t}(\mathrm{mg} / \mathrm{L})$ are the initial concentration and concentration at a certain time $(\mathrm{t})$ of the MG solution, $\mathrm{V}(\mathrm{L})$ is the volume of the MG solution, and $\mathrm{m}$ (g) is the mass of absorbent. 


\subsection{Adsorption of synthetic effluents}

Due to the actual industrial wastewater contains various ions, it is necessary to explore the adsorption capacity of the ZIF-67/cotton fibers in the synthetic effluents. The components present in the synthetic dye effluents was listed in Table 1.

\subsection{Evaluation of antibacterial activity}

For investigating the antibacterial activities of the ZIF$67 /$ cotton fibers, E. coli (gram-negative bacteria) and $S$. aureus (gram-positive bacteria) were selected as models in the inhibition zone test. Firstly, $100 \mathrm{~mL}$ of E. coli (ATCC8739) and S. aureus (ATCC6538) $\left(10^{8} \mathrm{CFU} / \mathrm{mL}\right.$ ) mother liquor were added to $900 \mathrm{~mL}$ of liquid medium, followed by activating for $12 \mathrm{~h}$. Subsequently, the activated mother liquor was diluted $10^{3}$ times to obtain the bacterial liquor with concentration of $10^{5} \mathrm{CFU} / \mathrm{mL}$. Next, $100 \mu \mathrm{L}$ of cultured bacterial solution was spread on an

Table 1 Chemical composition of the synthetic effluent

\begin{tabular}{lll}
\hline Dyes & $\boldsymbol{\lambda}_{\text {max }}(\mathbf{n m})$ & $\begin{array}{l}\text { Concentration } \\
\text { (mg/L) }\end{array}$ \\
\hline $\mathrm{MG}$ & 618 & 100 \\
$\mathrm{Na}_{2} \mathrm{CO}_{3}$ & & 10 \\
$\mathrm{CH}_{3} \mathrm{COONa}$ & 10 \\
$\mathrm{Na}_{2} \mathrm{SO}_{4}$ & 10 \\
$\mathrm{KNO}_{3}$ & 10 \\
$\mathrm{NaCl}$ & 10 \\
$\mathrm{Sodium}$ dodecyl sulfate & 10 \\
$\mathrm{KCl}$ & 10 \\
$\mathrm{~K}_{2} \mathrm{HPO}_{4}$ & 10 \\
$\mathrm{CaCl}_{2}$ & 10 \\
$\mathrm{MgSO}_{4} \cdot 7 \mathrm{H}_{2} \mathrm{O}$ & 10 \\
$\mathrm{Tap}^{-}$water &
\end{tabular}

agar plate. Finally, the ZIF-67/cotton fibers were tiled on a circular mold as solid culture plate for $12 \mathrm{~h}$ after ultraviolet sterilization for $15 \mathrm{~min}$. After that, the inhibition zone was measured. The inhibition zone tests were performed in triplicate.

\section{Results and discussion}

\subsection{Chemical composition of ZIF-67/cotton fibers}

Inspired from reported literature [32, 33], in this work, the facile and scalable in-situ growth of ZIF-67 on the cotton fibrous surfaces was developed via coordination replication strategy. The preparation route was illustrated in Scheme 1. First of all, a pre-deposited insoluble cobalt hydroxy carbonate $(\mathrm{CHC})$ as precursor layer was prepared via a mild solid/liquid interfacial reaction between $\mathrm{K}_{2} \mathrm{CO}_{3}$-impregnated cotton fibers and cobalt ion solution in ethanol. Then, it was employed as both the cobalt ion precursor and a template for the ZIF-67 growth. After treating with 2-methylimidazole (2-MIM) solution, the precursor layer morphology was reproduced to grow and anchor the ZIF-67 nanocrystals, resulting in formation of the targeted ZIF-67/cotton fiber composite. After preparation of the ZIF-67/cotton fibers, its chemical composition was confirmed by FTIR, XRD and XPS, respectively. Firstly, FTIR was employed to characterize the chemical structure of the ZIF-67/cotton fibers. As can be seen in Fig. 1a, for pristine cotton fibers, the characteristic band at $3303 \mathrm{~cm}^{-1}$ belonged to the hydroxy group $(\mathrm{O}-\mathrm{H})$ stretching vibration. For the $\mathrm{K}_{2} \mathrm{CO}_{3} /$ cotton fibers and $\mathrm{CHC} /$ cotton fibers, the characteristic bands at $1387-1363 \mathrm{~cm}^{-1}$ and $3514 \mathrm{~cm}^{-1}$ were attributed to the carbonate $\left(\mathrm{CO}_{3}{ }^{2-}\right)$ stretching vibration and hydroxy group $(\mathrm{O}-\mathrm{H})$ stretching vibration, respectively. These results suggested that an insoluble cobalt hydroxy carbonate $(\mathrm{CHC})$ precursor layer was successfully deposited
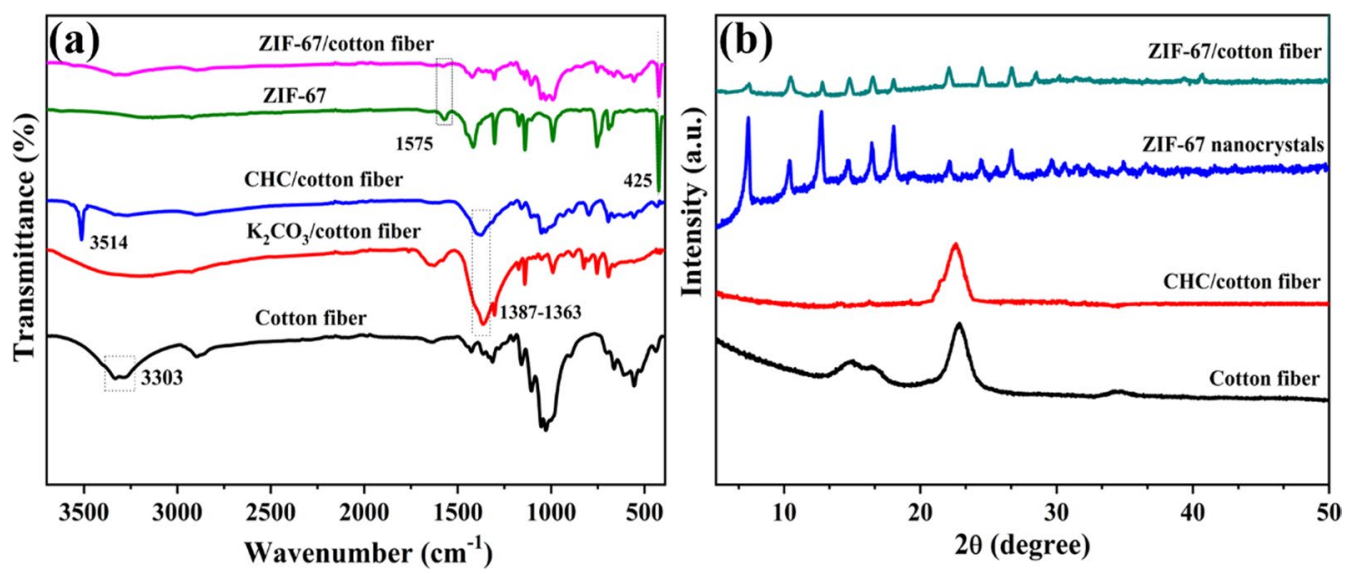

Fig. 1 FTIR spectra (a) and XRD patterns (b) of the samples 
on the cotton fibrous surfaces. After the in-situ growth of ZIF-67 nanocrystals on the cotton fibrous surfaces, new bands at $1575 \mathrm{~cm}^{-1}$ and $425 \mathrm{~cm}^{-1}$ appeared, which could be attributed to $\mathrm{C}=\mathrm{N}$ and $\mathrm{Co}-\mathrm{N}$ stretching vibration of the ZIF-67, respectively, indicating the successful growth of ZIF-67 nanocrystals on the cotton fibrous surfaces. Furthermore, XRD measurement was employed to analyze the crystalline structure of the as-synthesized ZIF$67 /$ cotton fibers. As shown in Fig. 1b, the cotton fibers had three obvious diffraction peaks at $2 \theta$ values of $14.7^{\circ}$, $16.4^{\circ}$ and $22.5^{\circ}$, ascribed to the (101), (10) $)$ and (002) planes of cellulose, respectively. After the in-situ growth of ZIF-67 nanocrystals, the representative crystalline diffraction peaks at $2 \theta=7.4^{\circ}, 10.4^{\circ}, 12.8^{\circ}, 14.8^{\circ}, 18.0^{\circ}, 22.1^{\circ}$ attributing to the (011), (002), (112), (022), (222), (114) planes could be observed, matching well with those of the pure ZIF-67 nanocrystals. These results further indicated that the ZIF-67 nanocrystals were successfully deposited on the surface of the cotton fiber, and the nanocrystal structure of ZIF-67 had no significant influence in the hybridization process.

Next, the chemical composition of the as-prepared ZIF-67/cotton fibers was further confirmed by XPS test (Fig. 2). As shown in Fig. 2a, besides the existence of $\mathrm{C}$ and $\mathrm{O}$ element belonging to the pristine cotton fibers [34], appearance of new peaks of the Co and $\mathrm{N}$ elements could be observed, indicating the growth of ZIF-67 nanocrystals on the cotton fibrous surfaces. The high-resolution spectra of Co 2p, C 1s and $\mathrm{N}$ 1s were presented in Fig. 2b-d. In Fig. 2b, two major peaks at 779.3 and $794.8 \mathrm{eV}$ represented Co $2 \mathrm{p}_{3 / 2}$ and Co $2 \mathrm{p}_{1 / 2}$, respectively. The $\mathrm{Co} 2 \mathrm{p}_{3 / 2}$ peak was derived from $\mathrm{Co}^{2+}$ species, a characteristic peak of the ZIF-67. The typical shake-up satellite peaks (denoted as "Sat.") of $\mathrm{Co}^{2+}$ could be observed at 785.0 and $801.8 \mathrm{eV}$. In Fig. 2c, the peaks at $285.2,284.5$ and $283.9 \mathrm{eV}$ of $\mathrm{C} 1 \mathrm{~s}$ were attributed to $\mathrm{C}-\mathrm{C}, \mathrm{C}-\mathrm{O}$, and sp3 $\mathrm{C}$, respectively. Moreover, the $\mathrm{N} 1$ s peak at 398.7 and $399.3 \mathrm{eV}$ (Fig. 2d) was assigned to the pyridinic and pyrolinic nitrogen from the ZIF-67/cotton fibers [35], respectively. These results were in excellent agreement with those from FTIR and XRD measurements, implying the successful fabrication of the targeted ZIF-67/cotton fibers.
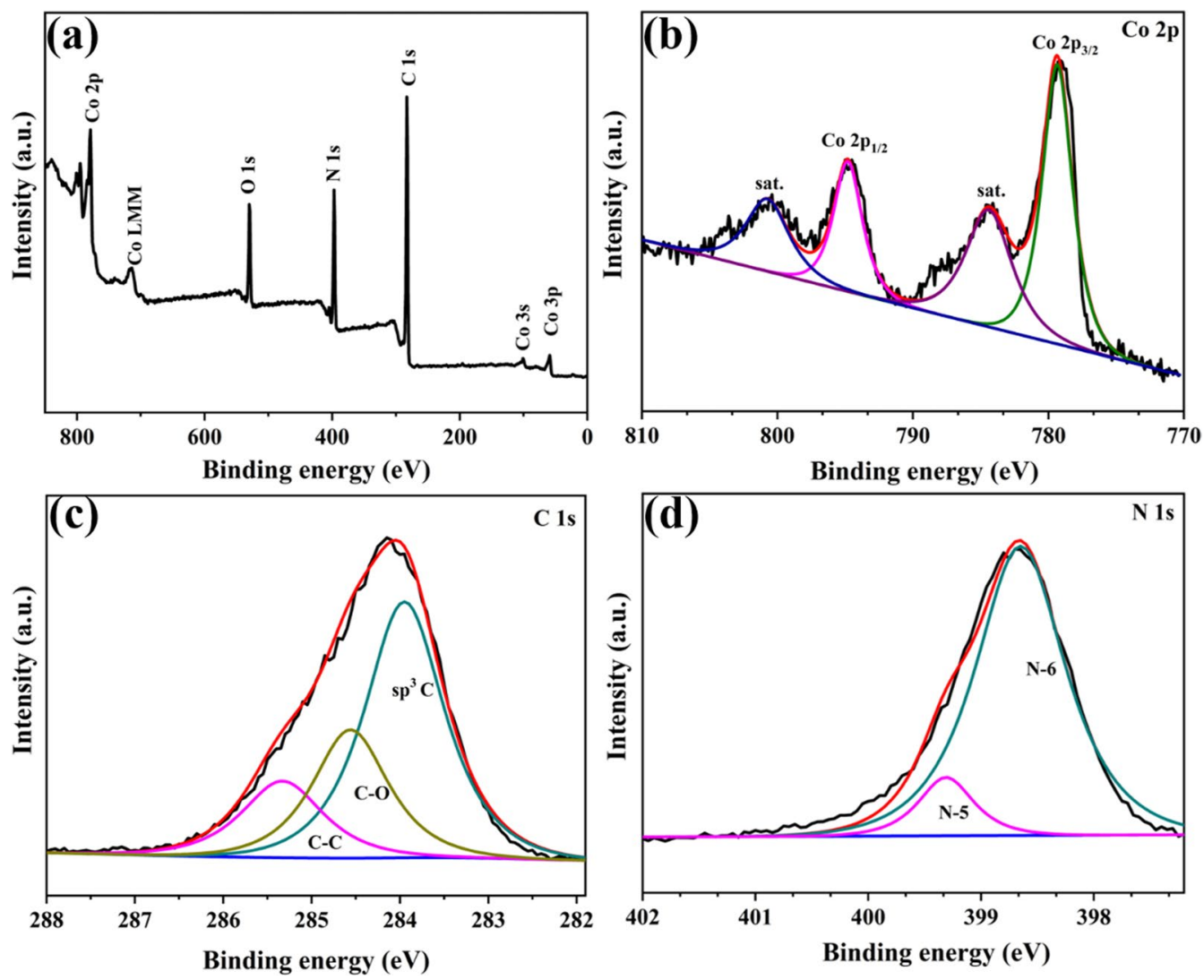

Fig. 2 XPS spectrum of the as-prepared ZIF-67/Cotton fibers (a) and corresponding high-resolution spectra: Co 2p (b), C 1 s (c) and N 1 s (d) 


\subsection{Surface morphology of ZIF-67/cotton fibers}

After confirming the chemical composition of the asprepared ZIF-67/cotton fibers, its micro-structure was visualized by SEM measurement. Meanwhile, the SEM images of the pristine cotton fibers and $\mathrm{CHC} /$ cotton fibers were also presented for comparison. The corresponding SEM images were illustrated in Fig. 3. It could be clearly seen that the initial cotton fibers exhibited smooth surface (Fig. 3a-c). Then, the formation of a dense rodlike coating on the cotton fibrous surfaces could be observed in the $\mathrm{CHC} /$ cotton fibers (Fig. $3 \mathrm{~d}-\mathrm{f}$ ), indicating existence of the precursor layer on the cotton fibrous surfaces. This result was also verified by XRD and FTIR tests. As expected, numerous the ZIF-67 nanocrystals

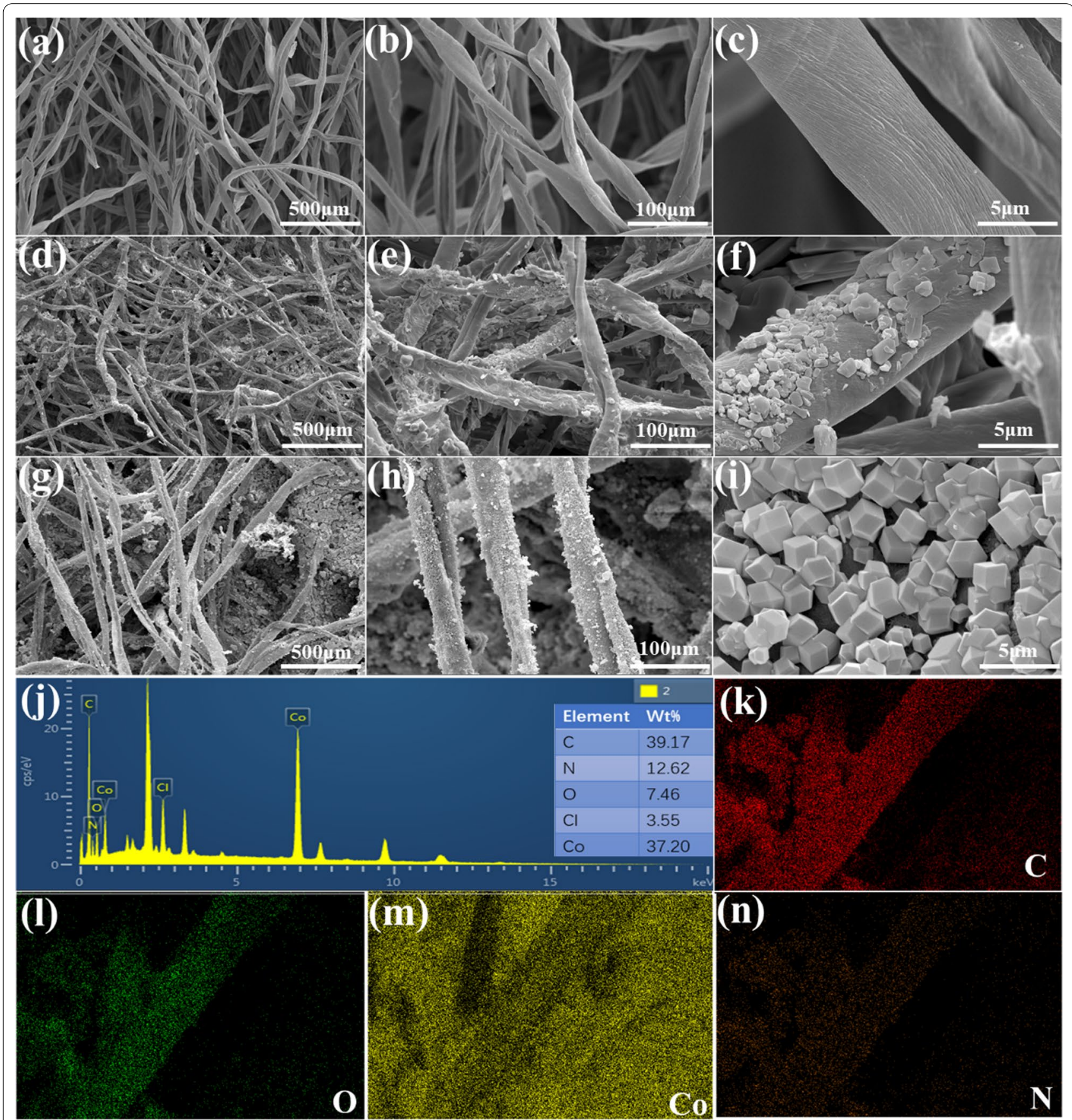

Fig. 3 SEM images of the pristine cotton fibers (a-c), CHC-deposited cotton fibers (d-f) and ZIF-67/cotton fibers ( $\mathbf{g}-\mathbf{i})$; EDS spectrum of the ZIF-67/ cotton fibers (j) and corresponding mapping images: C (k), O (I), Co (m), N (n) 
were successfully grown onto the cotton fibrous surfaces (Fig. $3 g-i)$. It is worth pointing out that the rhombic dodecahedron ZIF-67 nanocrystals could be found on the surfaces of the ZIF-67/cotton fiber (Fig. 3i), which were densely immobilized on the cotton fiber surfaces. Figure 3j presented the EDS spectrum of the ZIF-67/cotton fibers, and the corresponding EDS mapping images were displayed in Fig. $3 \mathrm{k}-\mathrm{n}$. It could be observed that Co element was uniformly distributed on the entire cotton fibrous surfaces (Fig. 3m). This result confirmed the ZIF-67 nanocrystals covered the cotton fibrous surfaces. The mapping of $\mathrm{N}$ element was attributed to the organic linker 2-methylimidazole, also implying the successful deposition of the ZIF-67 nanocrystals on the cotton fibrous surfaces. Until now, it could be concluded from above mentioned results that the ZIF-67/cotton fibers were successfully prepared. Noteworthily, in this work, the ZIF-67/cotton fibers can be facilely and inexpensively fabricated in a large scale (Additional file 1: Fig. S1), due to the adoption of such a simple coordination replication method.

\subsection{Surface area of ZIF-67/cotton fibers}

After successful preparation of the ZIF-67/cotton fibers, its surface area was investigated. It is well known that the specific surface area of material significantly influences its adsorption performance. Herein, nitrogen adsorption-desorption was employed to measure the Brunauer-Emmett-Teller (BET) surface area, and the result was shown in Fig. 4. It suggested that the micropores of ZIF-67 nanocrystals grown on the cotton fibers were accessible for the adsorption of $\mathrm{N}_{2}$ (Fig. 4a). Then, the BET surface areas of the pristine cotton fibers and ZIF-67/cotton fibers were calculated to be $1.32 \mathrm{~m}^{2} / \mathrm{g}$ and $237.29 \mathrm{~m}^{2} / \mathrm{g}$, respectively (Fig. 4b). The very high surface area value of the ZIF-67/cotton fibers compared to that of the pristine cotton fibers suggested that the ZIF-67/ cotton fibers contained micro and mesopores, providing more active sites and thereby enhanced the adsorption ability of the adsorbent.

\subsection{Adsorption kinetics}

Further, the adsorption behavior and adsorption capacity of the as-prepared ZIF-67/cotton fibers were investigated in detail. The contact time significantly affects the adsorption equilibrium and adsorption capacity. Therefore, the effect of adsorption time on the adsorption capacity of the ZIF-67/cotton fibers was investigated. As shown in Fig. $5 \mathrm{a}$, the fast adsorption in the initial stage of the ZIF-67/cotton fibers towards MG was ascribed to the sufficient free active sites and large surface area of the adsorbent at that time. Then, the remaining MG molecules were not easy to be adsorbed by the ZIF-67/ cotton fibers due to the insufficient active sites and the repulsive interaction between the adsorbed and free MG molecules, leading to a relatively long time to reach the adsorption equilibrium. The equilibrium adsorption capacity of the ZIF-67/cotton fibers was approximately $597 \mathrm{mg} / \mathrm{g}$, whereas, the pristine cotton fibers exhibited poor adsorption capacity for MG $(99 \mathrm{mg} / \mathrm{g})$, indicating the ZIF-67 nanocrystals played an essential role in removal of MG.

Based on the results from the effect of contact time on the adsorption of MG onto the ZIF-67/cotton fibers, its adsorption mechanism was further investigated by kinetics studies. Herein, the pseudo-first-order model and pseudo-second-order model are employed:

The pseudo-first-order model:

$$
\operatorname{In}\left(\mathrm{q}_{\mathrm{e}}-\mathrm{q}_{\mathrm{t}}\right)=\operatorname{Inq}_{\mathrm{e}}-\mathrm{k}_{1} / 2.303 \mathrm{t}
$$
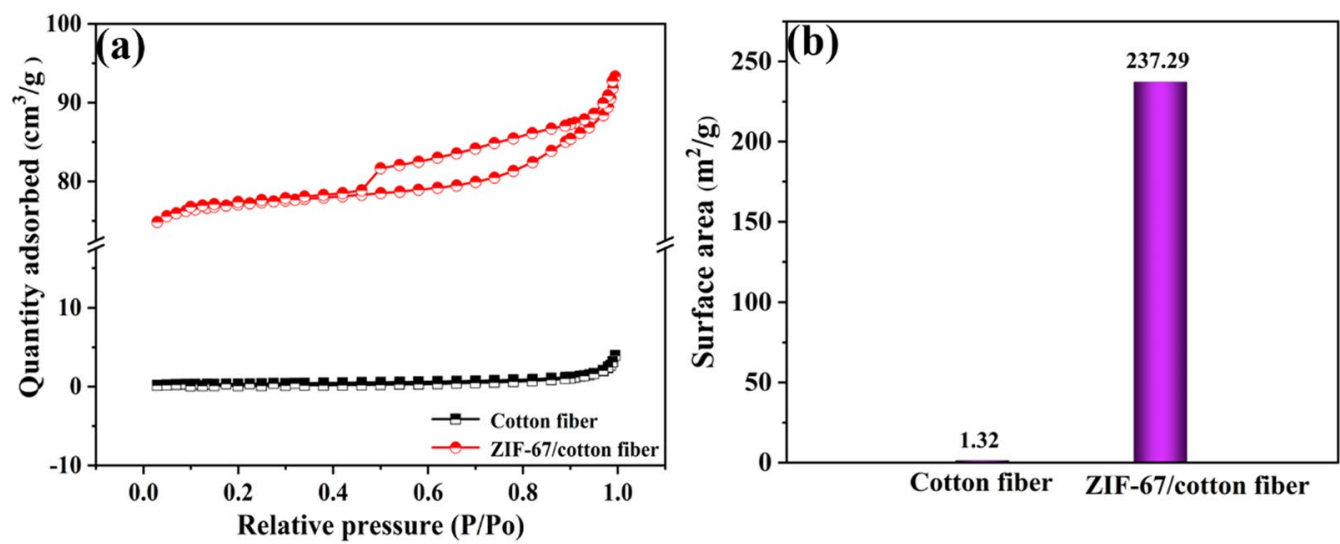

Fig. 4 Nitrogen adsorption-desorption of the pristine cotton fibers and ZIF-67/cotton fibers, respectively (a), BET surface areas of the pristine cotton fibers and ZIF-67/cotton fibers (b) 

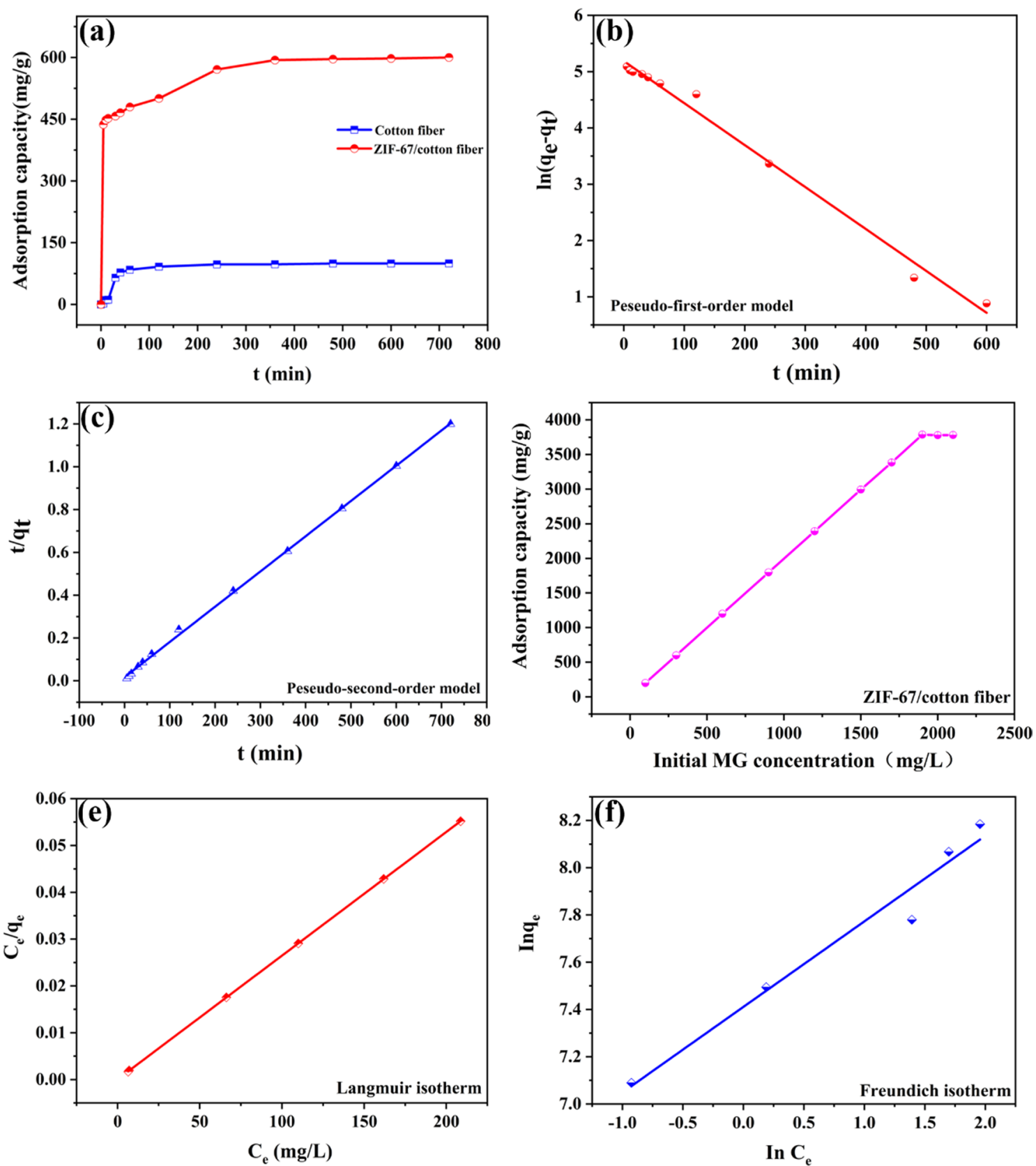

Fig. 5 Effect of contact time on the adsorption capacity of the ZIF-67/cotton fibers towards MG (a), the pseudo-first-order kinetic model (b) and pseudo-second-order kinetic model (c) for adsorption of MG by the ZIF-67/cotton fibers (adsorption conditions: mass of adsorbent, $100 \mathrm{mg}$; initial dye concentration, $300 \mathrm{mg} / \mathrm{L}$; volume of dye solution, $200 \mathrm{~mL}$ ); effect of initial MG concentration on the adsorption of MG onto ZIF-67/cotton fibers (d); Langmuir (e) and Freundlich (f) isothermal models for the adsorption of MG by the ZIF-67/cotton fibers (adsorption conditions: mass of adsorbent, $10 \mathrm{mg}$; initial dye concentration, $100-2100 \mathrm{mg} / \mathrm{L}$; volume of dye solution, $20 \mathrm{~mL}$ )

The pseudo-second-order model:

$$
\mathrm{t} / \mathrm{q}_{\mathrm{t}}=1 / \mathrm{k}_{2} \mathrm{q}_{\mathrm{e}}^{2}+\mathrm{t} / \mathrm{q}_{\mathrm{e}}
$$

where $\mathrm{q}_{\mathrm{e}}$ and $\mathrm{q}_{\mathrm{t}}$ are the adsorption capacities $(\mathrm{mg} / \mathrm{g})$ at equilibrium state and at time $\mathrm{t}(\mathrm{min})$, respectively. $\mathrm{k}_{1}$ $\left(\mathrm{min}^{-1}\right)$ and $\mathrm{k}_{2}\left(\mathrm{~g} \mathrm{mg}^{-1} \mathrm{~min}^{-1}\right)$ are the pseudo-first-order and pseudo-second-order rate constants, respectively. Figure $5 \mathrm{~b}$ and $\mathrm{c}$ showed that the plots of $\operatorname{In}\left(\mathrm{q}_{\mathrm{e}}-\mathrm{q}_{\mathrm{t}}\right)$ versus $t$ and $t / q_{t}$ versus $t$, respectively. The kinetic parameters and the correlation coefficients $\left(R^{2}\right)$ were summarized in Additional file 1: Table S1. It could be seen that the pseudo-second-order model fitted the experimental 
data of the ZIF-67/cotton fibers better than that of the pseudo-first-order model, due to the higher $\mathrm{R}^{2}$ value (0.99932). Morever, the theoretical adsorption capacity of the ZIF-67/cotton fibers based on the pseudo-secondorder model $(606.1 \mathrm{mg} / \mathrm{g})$, was closer to the practical experimental value $(597 \mathrm{mg} / \mathrm{g})$ compared to that of the pseudo-first-order model $(178.7 \mathrm{mg} / \mathrm{g})$. These results indicated that the adsorption of the ZIF-67/cotton fibers towards MG followed the pseudo-second-order model.

\subsection{Adsorption isotherm}

The effect of initial concentration of MG on the adsoprtion capacity of the ZIF-67/cotton fibers was shown in Fig. 5d. The adsorption capacity of the ZIF-67/cotton fibers towards MG gradually increased with the increment of MG concentration, then reached to a plateau. Based on this result, Langmuir and Freundlich models were employed and simulated with the experimental data to analyze the adsorption isotherm.

The Langmuir model:

$$
C_{e} / \mathrm{q}_{\mathrm{e}}=1 / \mathrm{q}_{\mathrm{m}} K_{L}+C_{e} / \mathrm{q}_{\mathrm{m}}
$$

The Freundlich model:

$$
\operatorname{Inq}_{\mathrm{e}}=\operatorname{InK} \mathrm{F}_{\mathrm{F}}+1 / \mathrm{n} * \operatorname{InC} \mathrm{e}_{\mathrm{e}}
$$

where $C_{e}(\mathrm{mg} / \mathrm{L})$ is the concentration of MG at equilibrium state, $\mathrm{q}_{\mathrm{e}}(\mathrm{mg} / \mathrm{g})$ and $\mathrm{q}_{\mathrm{m}}(\mathrm{mg} / \mathrm{g})$ are the amount adsorbed of the ZIF-67/cotton fibers at equilibrium and the maximum adsorption amount, respectively. $\mathrm{K}_{\mathrm{L}}(\mathrm{L} /$ $\mathrm{mg}$ ) is the Langmuir isotherm constant related to the free energy of adsorption. $\mathrm{K}_{\mathrm{F}}(\mathrm{mg} / \mathrm{g})$ is the Freundlich isotherm constant related to the adsorption capacity, and $\mathrm{n}$ is the Freundlich constant of the adsorption model related to the adsorption strength.

Figure $5 \mathrm{e}$ and $\mathrm{f}$ showed the linear plots of $\mathrm{C}_{\mathrm{e}} / \mathrm{q}_{\mathrm{e}}$ versus $\mathrm{C}_{\mathrm{e}}$ and $\ln \mathrm{q}_{\mathrm{e}}$ versus $\ln \mathrm{C}_{\mathrm{e}}$. The correlation coefficients $\left(\mathrm{R}^{2}\right)$ of the Langmuir and Freundlich isotherm models were listed in Additional file 1: Table S2. It can be seen that the Langmuir model exhibited better $R^{2}(0.99998)$ than that of the Freundlich model, which demonstrated that the Langmuir model was more suitable than Freundlich model to describe the adsorption behavior of organic dyes by the ZIF-67/cotton fibers, suggesting a monolayer adsorption of MG onto the ZIF-67/cotton fibers.

One can also see that the saturated adsorption capacity of MG calculated by the Langmuir adsorption isotherm model was $3795 \mathrm{mg} / \mathrm{g}$, which was consistent with that obtained from the experimental result $(3787 \mathrm{mg} / \mathrm{g})$. This good agreement further verified that the Langmuir isotherm model is more suitable to describe the adsorption of the ZIF-67/cotton fibers towards MG. Furthermore, to examine the competitiveness of the ZIF-67/cotton fibers with other adsorbents for the MG adsorption, Table 2
Table 2 Comparison of the adsorption capacity of the ZIF-67/ cotton fibers towards MG with other adsorbents

\begin{tabular}{lll}
\hline Adsorbent & $\mathbf{q}_{\mathbf{m a x}}(\mathbf{m g} \mathbf{g})$ & References \\
\hline ZIF-67/cotton & 3787 & In this work \\
ZIF-67/PAN fibers & 1305 & {$[36]$} \\
ZIF-67 nanoparticles & 2545 & {$[36]$} \\
ZIF-67 & 2500 & {$[28]$} \\
MIL-100(Fe) & 485 & {$[37]$} \\
Tb-MOF & 480 & {$[38]$} \\
ZIF-8/PAN nanofiber & 1666.67 & {$[39]$} \\
ZIF-8@chitosan/PVA nanofiber & 1000 & {$[40]$} \\
Fe-BTC MOF & 177 & {$[41]$} \\
Magnetic NH2-MIL-101(Al) & 274 & {$[42]$} \\
MIL-100(Fe) & 2090 & {$[43]$} \\
polyoxometalate@UiO-66 & 191 & {$[44]$} \\
\hline
\end{tabular}

$\mathrm{q}_{\max }$ is the maximum adsorption capacity of MG on adsorbent based onto the Langmuir model

listed the maximum adsorption capacity of MG with other adsorbents. It was obvious that the ZIF-67/cotton fibers exhibited excellent adsorption capacity towards MG.

\subsection{Effect of ionic strength on the adsorption capacity}

Herein, the effect of ionic strength on MG adsorption onto the ZIF-67/cotton fibers was investigated under various $\mathrm{NaCl}$ concentrations, as the existence of salts in industrial effluents possibly affects the adsorption process. Figure 6a presented that the removal efficiency of the ZIF-67/cotton fibers towards MG changed little in the presence of $\mathrm{NaCl}$ in the MG solution. Even though the concentration of $\mathrm{NaCl}$ was increased to $6 \mathrm{~mol} / \mathrm{L}$, the removal efficiency remained stable. It suggested that the effect of ionic strength was insignificant to the adsorption of the ZIF-67/cotton fibers towards MG. Thus, MG adsorption might not be ascribed to the electrostatic interaction.

\subsection{Effect of $\mathrm{pH}$ on the adsorption capacity}

Undeniably, the $\mathrm{pH}$ value of the wastewater has a noticeable role in the removal of dyes. Under different $\mathrm{pH}$ values, not only the ionic or neutral state of the target compound is changed, but also the surface charge of the adsorbent may be changed as well. And it will promote or inhibit the interaction between the adsorbate and the adsorbent, resulting in the difference of the adsorption capacity and performance. In a previous report, ZIF-67 nanocrystals exhibited structural instability under the strong acidic environment (i.e., soaked in a solution at $\mathrm{pH}=2$ for $30 \mathrm{~s}$ ) [45]. Moreover, the original color of MG changes from aquamarine blue to transparency at a $\mathrm{pH}$ 

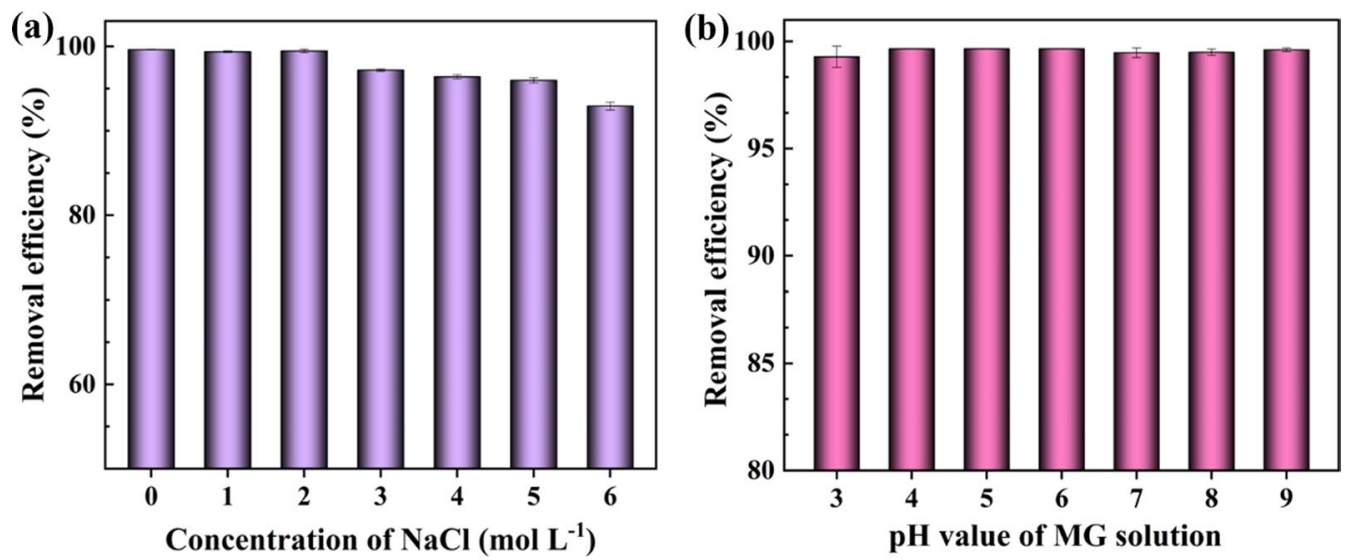

Fig. 6 Effects of ionic strength (a) and pH (b) on the removal efficiency of the ZIF-67/cotton fibers towards MG (adsorption conditions: mass of adsorbent, $10 \mathrm{mg}$; initial dye concentration, $100 \mathrm{mg} / \mathrm{L}$; volume of dye solution, $20 \mathrm{~mL}$ )

value above 10 [28], which was aligned with the result in Additional file 1: Fig. S2. Additionally, a common pH range of wastewater is from 4 to 9 [28]. Therefore, the adsorption experiments with different $\mathrm{pH}$ values were performed at $\mathrm{pH}=3-9$ in this study. Figure $6 \mathrm{~b}$ displayed that the removal efficiency of the ZIF-67/cotton fibers towards MG changed little under different $\mathrm{pH}$ values. Noteworthily, the removal efficiency of the ZIF-67/cotton fibers showed no significant decrement in acid and alkaline environments, also proving that MG adsorption might not be ascribed to the electrostatic interaction between the ZIF-67/cotton fibers and MG molecules.

\subsection{Adsorption mechanism}

According to the analyses of the adsorption kinetics and adsorption isotherm, the adsorption process of the ZIF$67 /$ cotton fibers was mainly controlled by the chemical adsorption mechanism. However, the ionic strength and $\mathrm{pH}$ value showed no significant influence on the adsorption performance of the ZIF-67/cotton fibers towards $M G$, suggesting that the electrostatic interaction was not the main mechanism for removal of MG. Therefore, there might be some other interaction forces that caused MG to be adsorbed onto the ZIF-67/cotton fibers. Lin et al. showed that ZIF-67 was chamfered cubic and these cubes consisted of 2-MIM, which was connected to cobalt ions [28]. The imidazole ring of the 2-MIM involves two double bonds and a pair of electrons from the pronated nitrogen, while all interactions are on the plane of the imidazole ring. Therefore, the high adsorptive removal of MG by the ZIF-67/cotton fibers might be attributed to the imidazole ring as an aromatic compound, which could interact with other aromatic compounds via the $\pi-\pi$ stacking interaction. To conclude, $\pi-\pi$ stacking interaction might be the main factor causing MG adsorption onto the ZIF-67/cotton fibers. Actually, the $\pi-\pi$ stacking interaction is used to explain the high adsorption capacity of adsorbents which contain the $\mathrm{sp}^{2}$ hybridization of carbon with adsorbates containing aromatic rings in their molecular structure [46]. Moreover, ZIF-67 nanocrystals grow evenly on the surface of the cotton fibers using an easy coordination replication strategy to better contact with the dye molecules in water, leading the fast and highly efficient adsorption.

\subsection{Recyclability}

Recyclability of absorbent is also a critical property in the practical applications, especially in terms of cost. For this purpose, the reusability of the ZIF-67/cotton fibers towards MG was investigated in detail. To regenerate the MG adsorbed ZIF-67/cotton fibers, simple ethanol washing method was employed to desorption. The evaluation of adsorption capacity with increasing cycle times was presented in Fig. 7a. The ZIF-67/cotton fibers exhibited a preeminent recyclable performance without apparent decrease in the adsorption capacity. After ten regeneration cycles, the removal efficiency of the ZIF-67/cotton fibers towards MG could still remain over $90 \%$ and the color of the ZIF-67/cotton fibers barely changed (Fig. 7b) that indicated it has great durability in the water solution. Moreover, as illustrated in Additional file 1: Fig. S3, after 10 successive cycles adsorption-desorption, the XRD pattern of the regenerated ZIF-67/cotton fiber was in agreement with the diffraction curve of the initial ZIF-67/cotton fiber. In addition, Additional file 1: Fig. S3 showed that many ZIF-67 nanocrystals were still immobilized on the surface of the cotton fiber even after cyclic adsorption. The morphology of the ZIF-67 nanocrystal almost remained unchanged compared with that of the pristine state. These results signified the outstanding 

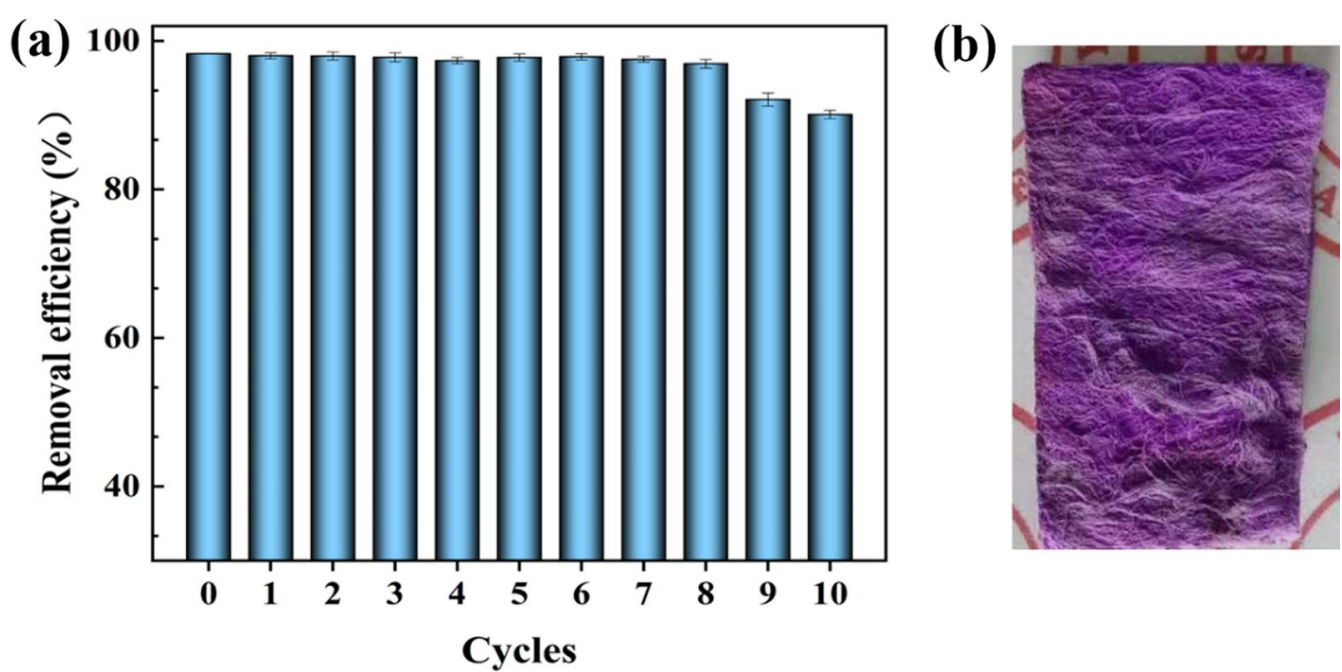

Fig. 7 Removal efficiency of the regenerated ZIF-67/cotton fibers toward MG (a) and the optical image of the ZIF-67/cotton fibers (b) after 10 successive adsorption-desorption cycles (adsorption conditions: mass of adsorbent, 100 mg; initial dye concentration, 20 mg/L; volume of dye solution, $50 \mathrm{~mL}$ )

recyclability of the ZIF-67/cotton fibers for MG adsorption applications.

\subsection{Dynamic adsorption}

In order to further investigate the removal capacity of the ZIF-67/cotton towards MG, the dynamic adsorption performance of the ZIF-67/cotton fibers was investigated. Typically, the ZIF-67/cotton fibers were filled into a syringe as a filter, and then $10 \mathrm{~mL}$ of MG solution $(100 \mathrm{mg} / \mathrm{L})$ was passed through the ZIF-67/ cotton fibers packed filter. In this work, due to relatively slow the adsorption rate, so the dynamic adsorption repeated three times. As we could see in Fig. 8a-d, the color of MG solution changed from aquamarine blue to

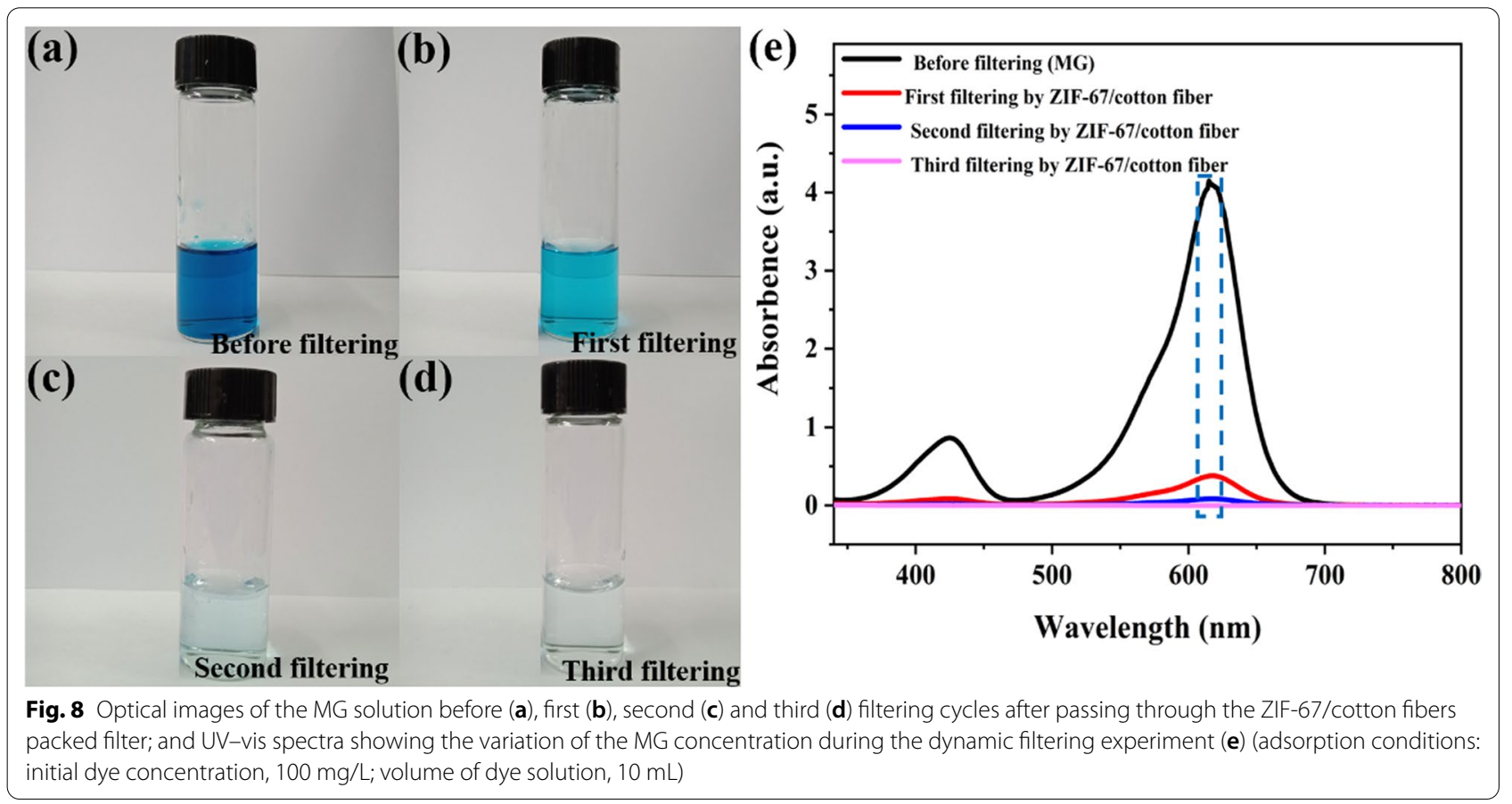


transparent after three cycles, with the MG removal efficiency reaching $100 \%$. Meanwhile, as shown in Fig. 8e, the characteristic adsorption peak at $618 \mathrm{~nm}$ assigned to MG completely disappeared after three filtering cycles, further indicating the ZIF-67/cotton fibers had excellent adsorption capacity towards MG.

\subsection{Adsorption of synthetic dye effluent}

To check the usefulness of adsorbent in real applications, the adsorption performance of the ZIF-67/cotton fibers towards MG was conducted in the simulated dye effluent. The synthetic effluent was composed of MG, various salts and surfactants defined in Table 1 . The results were illustrated in Fig. 9. The color of MG solution changed from aquamarine blue to transparent after adsorbed by the ZIF-67/cotton fibers in Fig. 9a and b. The ZIF-67/cotton fibers were able to remove over $90 \%$ of MG from the simulated dye effluent even after 10 successive adsorption-desorption cycles (Fig. 9c). Therefore, the ZIF-67/ cotton fiber as an adsorbent possesses promising prospect in the colored wastewater treatment.

\subsection{Antibacterial activity}

After bacterial contamination, a solid biofilm layer can be formed on the surface of the material, resulting in its weak performance and short service life. Hence, adsorbents with excellent antibacterial activity can efficiently prolong its life time. Herein, the antibacterial activity of the ZIF-67/cotton fibers was determined using a disc diffusion method on a Mueller Hinton Agar (MHA) plate. The antibacterial activity of the materials was assessed by the diameter of the inhibition zone. Figure 10 presented that the transparent and uniform bacteriostatic circles were formed around the ZIF-67/cotton fibers against

\section{(a)}

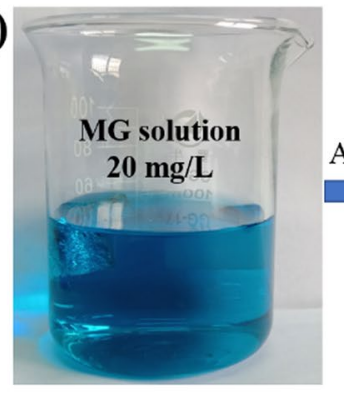

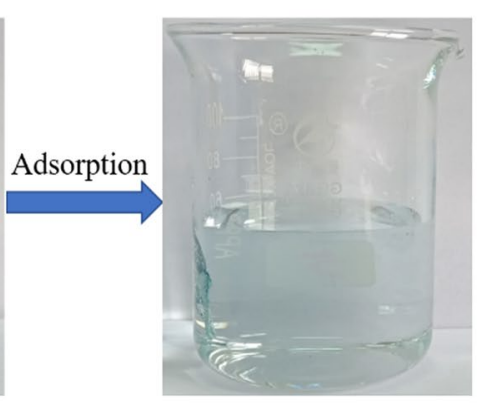

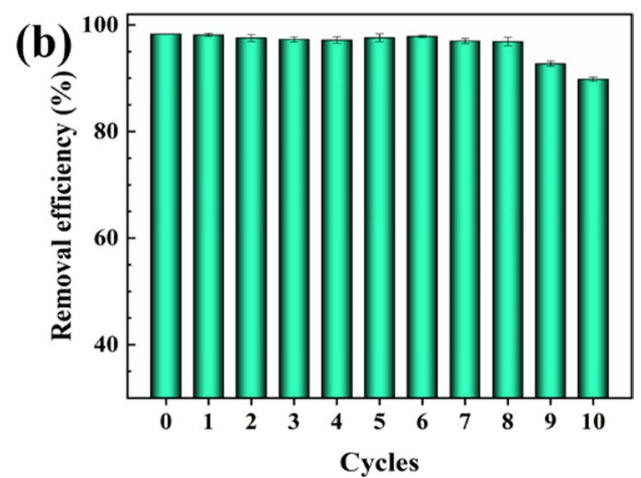

Fig. 9 Optical images of synthetic dye effluents adsorption (a) and removal efficiency of the regenerated ZIF-67/cotton fibers toward MG after 10 successive adsorption-desorption cycles in the simulated dye effluent (b) (adsorption conditions: mass of adsorbent, 100 mg; initial dye concentration, $20 \mathrm{mg} / \mathrm{L}$; volume of dye solution, $50 \mathrm{~mL}$ )
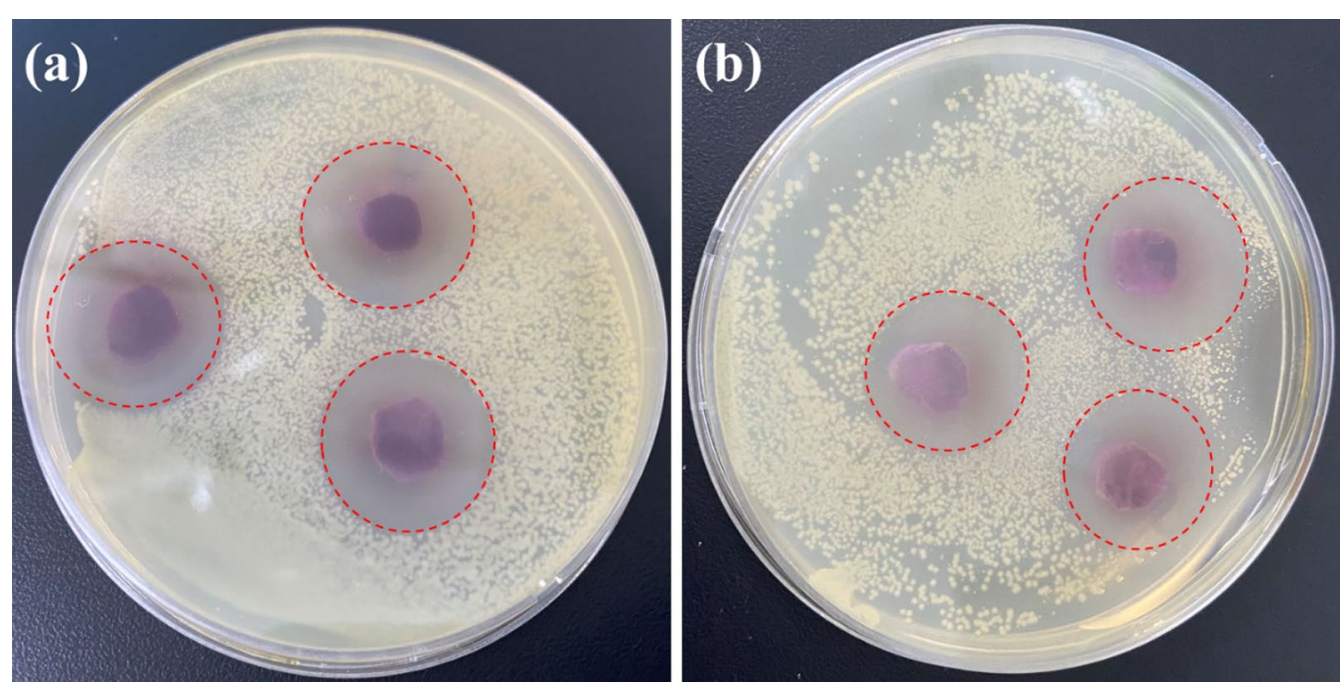

Fig. 10 Antibacterial activity of the ZIF-67/cotton fibers against E. coli (a) and S. aureus (b) 
both E. coli (Fig. 10a) and S. aureus (Fig. 10b). The transition metal-based ZIF-67 released the transition metal ion $\mathrm{Co}^{2+}$, which could kill the bacteria by destroying the liquid membrane of bacteria, endowing the antibacterial activity of the ZIF-67/cotton fibers. Additional file 1: Table S3 concluded the inhibition-zone ranges for the ZIF-67/cotton fibers against both bacteria. These results indicated that the ZIF-67/cotton fibers possessed outstanding antibacterial performances against $E$. coli and $S$. aureus.

\section{Conclusions}

In this work, the ZIF-67/cotton fibers were successfully prepared in a large scale by a simple coordination replication method at room temperature. Then, it was employed as an efficient adsorbent for removal of MG. The maximum adsorption capacity of the as-prepared ZIF-67/ cotton fibers towards MG was approximately $3787 \mathrm{mg} / \mathrm{g}$, superior to numerous adsorbents reported in previous literatures. The adsorption mechanism was mainly attributed to the $\pi-\pi$ stacking interactions between ZIF-67 and the aromatic framework of MG molecules. Moreover, the results showed that the adsorption capacity of the ZIF-67/cotton fibers towards MG was insignificantly influenced by ionic strength and $\mathrm{pH}$. Notably, the ZIF$67 /$ cotton fibers displayed the ability for highly efficient removal of MG from the synthetic effluents, indicating the potential possibility to be applied in the practical industrial wastewater treatment. In addition, the ZIF-67/ cotton fibers exhibited outstanding reusability and excellent antimicrobial performance. The ZIF-67/cotton fibers still maintained approximately $90 \%$ adsorption efficiency even after 10 cycles. Therefore, it can be concluded that the ZIF-67/cotton fibers with outstanding comprehensive performances may be a promising candidate to separate MG dye from contaminated wastewater.

\begin{abstract}
Abbreviations
MG: Malachite green; MOFs: Metal-organic frameworks; ZIFs: Zeolitic imidazolate frameworks; CHC: Cobalt hydroxy carbonate; E. coli: Gram-negative bacteria; S. aureus: Gram-positive bacteria; SEM: Scanning electron microscope; FTIR: Fourier transform infrared; XRD: X-ray diffraction; XPS: X-ray photoelectron spectroscopy; BET: Brunauer-Emmett-Teller.
\end{abstract}

\section{Supplementary Information}

The online version contains supplementary material available at https://doi. org/10.1186/s42825-021-00069-w.

Additional file 1. The supporting information include preparation of ZIF67 nanocrystals, 3 figures and 3 tables. Preparation of ZIF-67 nanocrystals. Fig. S1. Optical images of a large-scale fabrication of the ZIF-67/ cotton fiber. Fig. S2. Optical images of the color change of MG solution after adjusting the $\mathrm{pH}$ from 4 to $10-11$. Fig. S3. XRD pattern (a) and SEM images (b) of the ZIF-67/cotton fibers after successive adsorption-desorption cycles. Table S1. The parameters of kinetics for adsorption of MG onto ZIF$67 /$ cotton fibers. Table S2. The fitting results of isotherms for adsorption of MG onto ZIF-67/cotton fibers. Table S3. Range of inhibition zones of ZIF-67/cotton against $E$. coli and S. aureus.

\section{Acknowledgements}

The authors would like to thank the Analytical \& Testing Center of Sichuan University for XPS and SEM measurements. We also thank Dr. Sha Deng and Hongyan Xiao for experimental assistance.

\section{Authors' contributions}

LLH and LSJ conceived and designed the outline. LLH performed the experiments and write this manuscript. LWW and LSJ reviewed and edited the manuscript. YL, ZR, SJJ, DBJ and LHY proposed opinions. All authors read and approved the final manuscript.

\section{Funding}

This work is financially supported by the National Natural Science Foundation of China (No. 52003171), Fundamental Research Funds for the Central Universities, China (No. YJ201823; YJ201959), Sichuan Province Science and Technology Support Program, China (No. 2020YJ0316; 2021YJ0290) and the Science and Technology Cooperation Project between Sichuan University and Zigong City (No: 2019CDZG-23).

\section{Availability of data and materials}

All data generated or analyzed during this study are included in this published article and its supplementary information files.

\section{Declarations}

\section{Competing interests}

The authors declare that they have no competing interests.

\section{Author details}

${ }^{1}$ College of Biomass Science and Engineering, Sichuan University, Chengdu 610065, People's Republic of China. ${ }^{2}$ National Engineering Laboratory for Clean Technology of Leather Manufacture, Sichuan University, Chengdu 610065, People's Republic of China.

Received: 12 May 2021 Accepted: 10 September 2021

Published online: 15 November 2021

\section{References}

1. Xiang L, Lin J, Yang Q, Lin S, Chen S, Yan B. Facile preparation of hierarchical porous polydopamine microspheres for rapid removal of chromate from the wastewater. J Leather Sci Eng. 2020;2. https://doi.org/10.1186/ s42825-020-00036-x.

2. Karunanidhi A, David PS, Fathima NN. Electrospun keratin-polysulfone blend membranes for treatment of tannery effluents. Water Air Soil Pollut. 2020;231. https://doi.org/10.1007/s11270-020-04682-z

3. Mahmoudabadi TZ, Talebi P, Jalili M. Removing Disperse red 60 and Reactive blue 19 dyes removal by using Alcea rosea root mucilage as a natural coagulant. J Leather Sci Eng. 2019;9. https://doi.org/10.1186/ s13568-019-0839-9.

4. Zhang J, Li Y, Zhang C, Jing Y. Adsorption of malachite green from aqueous solution onto carbon prepared from Arundo donax root. J Hazard Mater. 2008;150:774-82. https://doi.org/10.1016/j.jhazmat.2007.05.036.

5. Li C, Xiong Z, Zhang J, Wu C. The strengthening role of the amino group in metal-organic framework MIL-53 (Al) for methylene blue and malachite green dye adsorption. J Chem Eng Data. 2015;60:3414-22. https:// doi.org/10.1021/acs.jced.5b00692.

6. Zhou Y, Wang X, Zhang M, Jin Q, Gao B, Ma T. Removal of Pb(II) and malachite green from aqueous solution by modified cellulose. Cellulose. 2014;21:2797-809. https://doi.org/10.1007/s10570-014-0282-7. 
7. Appleman TD, Dickenson ERV, Bellona C, Higgins CP. Nanofiltration and granular activated carbon treatment of perfluoroalkyl acids. J Hazard Mater. 2013;260:740-6. https://doi.org/10.1016/j.jhazmat.2013.06.033.

8. Martins RC, Quinta-Ferreira RM. Remediation of phenolic wastewaters by advanced oxidation processes (AOPs) at ambient conditions: comparative studies. Chem Eng Sci. 2011;66:3243-50. https://doi.org/10.1016/j. ces.2011.02.023.

9. Trojanowicz M, Bojanowska-Czajka A, Bartosiewicz I, Kulisa K. Advanced Oxidation/Reduction Processes treatment for aqueous perfluorooctanoate (PFOA) and perfluorooctanesulfonate (PFOS) - a review of recent advances. Chem Eng J. 2017;2018(336):170-99. https://doi.org/10.1016/j. cej.2017.10.153

10. Zhan Y, Lan J, Shang J, Yang L, Guan X, Li W, et al. Durable ZIF-8/Ag/ $\mathrm{AgCl} / \mathrm{TiO} 2$ decorated PAN nanofibers with high visible light photocatalytic and antibacterial activities for degradation of dyes. J Alloys Compd. 2020;822: 153579. https://doi.org/10.1016/j.jallcom.2019. 153579.

11. Du Z, Cui C, Zhang S, Xiao H, Ren E, Guo R, et al. Visible-light-driven photocatalytic degradation of rhodamine B using Bi2WO6/GO deposited on polyethylene terephthalate fabric. J Leather Sci Eng. 2020;2. https://doi.org/10.1186/s42825-020-00029-w.

12. Zhang L, Yue Q, Yang K, Zhao P, Gao B. Enhanced phosphorus and ciprofloxacin removal in a modified BAF system by configuring Fe-C micro electrolysis: investigation on pollutants removal and degradation mechanisms. J Hazard Mater. 2018;342:705-14. https://doi.org/10. 1016/j.jhazmat.2017.09.010

13. Lima VN, Rodrigues CSD, Madeira LM. Simultaneous treatment of toluene-containing gas waste and industrial wastewater by the Fenton process. Sci Total Environ. 2020;749:2021. https://doi.org/10.1016/j. scitotenv.2020.141497.

14. Idel-aouad R, Valiente M, Yaacoubi A, Tanouti B, López-Mesas M. Rapid decolourization and mineralization of the azo dye C.I. acid red 14 by heterogeneous Fenton reaction. J Hazard Mater. 2011;186:745-50. https://doi.org/10.1016/j.jhazmat.2010.11.056.

15. Dehbi A, Dehmani Y, Omari H, Lammini A, Elazhari K, Abdallaoui A. Hematite iron oxide nanoparticles (a-Fe2O3): Synthesis and modelling adsorption of malachite green. J Environ Chem Eng. 2020;8: 103394 https://doi.org/10.1016/j.jece.2019.103394.

16. Al-Yousef HA, Alotaibi BM, Alanazi MM, Aouaini F, Sellaoui L, BonillaPetriciolet A. Theoretical assessment of the adsorption mechanism of ibuprofen, ampicillin, orange $\mathrm{G}$ and malachite green on a biomass functionalized with plasma. J Environ Chem Eng. 2021;9: 104950. https://doi.org/10.1016/j.jece.2020.104950.

17. Gupta VK. Application of low-cost adsorbents for dye removal-a review. J Environ Manag. 2009;90:2313-42. https://doi.org/10.1016/j. jenvman.2008.11.017.

18. Li Y, Zhou K, He M, Yao J. Synthesis of ZIF-8 and ZIF-67 using mixedbase and their dye adsorption. Microporous Mesoporous Mater. 2016;234:287-92. https://doi.org/10.1016/j.micromeso.2016.07.039.

19. Li J, Yu X, Zhu Y, Fu X, Zhang Y. 3D-2D-3D BiOl/porous g-C3N4/graphene hydrogel composite photocatalyst with synergy of adsorptionphotocatalysis in static and flow systems. J Alloys Compd. 2021;850: 156778. https://doi.org/10.1016/j.jallcom.2020.156778.

20. Salim NAA, Puteh MH, Khamidun MH, Fulazzaky MA, Abdullah NH, Yusoff ARM, et al. Interpretation of isotherm models for adsorption of ammonium onto granular activated carbon. Biointerface Res Appl Chem. 2021;11:9227-41. https://doi.org/10.33263/BRIAC112.92279241.

21. Xia K, Liu X, Chen Z, Fang L, Du H, Zhang X. Efficient and sustainable treatment of anionic dye wastewaters using porous cationic diatomite. J Taiwan Inst Chem Eng. 2020;113:8-15. https://doi.org/10.1016/j.jtice. 2020.07.020.

22. Zhao R, Shi X, Ma T, Rong H, Wang Z, Cui F, et al. Constructing mesoporous adsorption channels and MOF-polymer interfaces in electrospun composite fibers for effective removal of emerging organic contaminants. ACS Appl Mater Interfaces. 2021;13:755-64. https://doi. org/10.1021/acsami.0c20404

23. Lange LE, Kay OS. Degradation studies of methyl parathion with CUBTC metal-organic framework. J Environ Chem Eng. 2015;3:541-7. https:// doi.org/10.1016/j.jece.2015.01.007

24. Mirsoleimani-Azizi SM, Setoodeh P, Zeinali S, Rahimpour MR. Tetracycline antibiotic removal from aqueous solutions by MOF-5: adsorption isotherm, kinetic and thermodynamic studies. J Environ Chem Eng. 2018;6:6118-30. https://doi.org/10.1016/j.jece.2018.09.017.

25. Qu F, Zhu L, Yang K. Adsorption behaviors of volatile organic compounds (VOCs) on porous clay heterostructures (PCH). J Hazard Mater. 2009;170:7-12. https://doi.org/10.1016/j.jhazmat.2009.05.027.

26. Hassan N, Shahat A, El-Didamony A, El-Desouky MG, El-Bindary AA. Equilibrium, kinetic and thermodynamic studies of adsorption of cationic dyes from aqueous solution using ZIF-8. Moroccan J Chem. 2020;8:624-35. https://doi.org/10.48317/IMIST.PRSM/morjchem-v8i3. 21127.

27. Zhang T, Jin X, Owens G, Chen Z. Remediation of malachite green in wastewater by ZIF-8@Fe/Ni nanoparticles based on adsorption and reduction. J Colloid Interface Sci. 2021:210509. https://doi.org/10. 1016/j.jcis.2021.03.065.

28. Lin KYA, Chang HA. Ultra-high adsorption capacity of zeolitic imidazole framework-67 (ZIF-67) for removal of malachite green from water. Chemosphere. 2015;139:624-31. https://doi.org/10.1016/j.chemosphere. 2015.01.041.

29. Jhinjer HS, Singh A, Bhattacharya S, Jassal M, Agrawal AK. Metalorganic frameworks functionalized smart textiles for adsorptive removal of hazardous aromatic pollutants from ambient air. J Hazard Mater. 2020;2021(411): 125056. https://doi.org/10.1016/j.jhazmat.2021. 125056.

30. Emam HE, Darwesh OM, Abdelhameed RM. Protective cotton textiles via amalgamation of cross-linked zeolitic imidazole frameworks. Ind Eng Chem Res. 2020;59:10931-44. https://doi.org/10.1021/acs.iecr. Oc01384

31. Son YR, Ryu SG, Kim HS. Rapid adsorption and removal of sulfur mustard with zeolitic imidazolate frameworks ZIF-8 and ZIF-67. Microporous Mesoporous Mater. 2019;2020(293): 109819. https://doi.org/10. 1016/j.micromeso.2019.109819.

32. Ma K, Wang Y, Chen Z, Islamoglu T, Lai C, Wang X, et al. Facile and scalable coating of metal-organic frameworks on fibrous substrates by a coordination replication mrethod at room temperature. ACS Appl Mater Interfaces. 2019. https://doi.org/10.1021/acsami.9b04780.

33. Reboul J, Furukawa S, Horike N, Tsotsalas M, Hirai K, Uehara H, et al. Mesoscopic architectures of porous coordination polymers fabricated by pseudomorphic replication. Nat Mater. 2012;11:717-23. https://doi. org/10.1038/NMAT3359.

34. Cai Q, Yang S, Zhang C, Li Z, Li X, Shen Z, et al. Facile and versatile modification of cotton fibers for persistent antibacterial activity and enhanced hygroscopicity. ACS Appl Mater Interfaces. 2018;10:3850616. https://doi.org/10.1021/acsami.8b14986.

35. Sankar SS, Keerthana G, Manjula K, Sharad JH, Kundu S. Electrospun Fe-incorporated ZIF-67 nanofibers for effective electrocatalytic water splitting. Inorg Chem. 2021;60:4034-46. https://doi.org/10.1021/acs. inorgchem.1 000097

36. Jin L, Ye J, Wang Y, Qian X, Dong M. Electrospinning synthesis of ZIF-67/ PAN fibrous membrane with high-capacity adsorption for malachite green. Fibers Polym. 2019;20:2070-7. https://doi.org/10.1007/ s12221-019-1196-7.

37. Huo SH, Yan XP. Metal-organic framework MIL-100(Fe) for the adsorption of malachite green from aqueous solution. J Mater Chem. 2012;22:7449-55. https://doi.org/10.1039/c2jm16513a.

38. Mohammadnejad M, Hajiashrafi T, Rashnavadi R. Highly efficient determination of malachite green in aquatic product using Tb-organic framework as sorbent. J Porous Mater. 2018;25:1771-81. https://doi. org/10.1007/s10934-018-0590-7.

39. Zhan $Y$, Guan $X$, Ren E, Lin $S$, Lan J. Fabrication of zeolitic imidazolate framework-8 functional polyacrylonitrile nanofibrous mats for dye removal. J Polym Res. 2019;26. https://doi.org/10.1007/ s10965-019-1806-5.

40. Mahmoodi NM, Oveisi M, Taghizadeh A, Taghizadeh M. Synthesis of pearl necklace-like ZIF-8@chitosan/PVA nanofiber with synergistic effect for recycling aqueous dye removal. Carbohydr Polym. 2019:2020(227): 115364. https://doi.org/10.1016/j.carbpol.2019.115364.

41. Delpiano GR, Tocco D, Medda L, Magner E, Salis A. Adsorption of malachite green and alizarin red $s$ dyes using fe-btc metal organic framework as adsorbent. Int J Mol Sci. 2021;22:1-16. https://doi.org/10. 3390/ijms22020788. 
42. Liu H, Chen L, Ding J. Adsorption behavior of magnetic amino-functionalized metal-organic framework for cationic and anionic dyes from aqueous solution. RSC Adv. 2016;6:48884-95. https://doi.org/10.1039/ c6ra07567c.

43. Huo SH, Liu CX, Zhou PX, Yu J, Bai L, Han ZG, et al. Recyclable magnetic carbonaceous porous composites derived from MIL-100(Fe) for superior adsorption and removal of malachite green from aqueous solution. RSC Adv. 2019;9:23711-7. https://doi.org/10.1039/c9ra04310a.

44. Zeng L, Xiao L, Long Y, Shi X. Trichloroacetic acid-modulated synthesis of polyoxometalate@UiO-66 for selective adsorption of cationic dyes. J Colloid Interface Sci. 2018;516:274-83. https://doi.org/10.1016/j.jcis. 2018.01.070

45. Lei Z, Feng J, Yang Y, Shen J, Zhang W, Wang C. An efficient polymer coating for highly acid-stable zeolitic imidazolate frameworks based composite sponges. J Hazard Mater. 2019;2020(382): 121057. https:// doi.org/10.1016/j.jhazmat.2019.121057.

46. Thanh Tu NT, Thien TV, Du PD, Thanh Chau VT, Mau TX, Khieu DQ. Adsorptive removal of congo red from aqueous solution using zeolitic imidazolate framework-67. J Environ Chem Eng. 2018;6:2269-80. https:// doi.org/10.1016/j.jece.2018.03.031.

\section{Publisher's Note}

Springer Nature remains neutral with regard to jurisdictional claims in published maps and institutional affiliations.

\section{Submit your manuscript to a SpringerOpen ${ }^{\circ}$ journal and benefit from:}

- Convenient online submission

- Rigorous peer review

- Open access: articles freely available online

- High visibility within the field

- Retaining the copyright to your article

Submit your next manuscript at $\boldsymbol{\nabla}$ springeropen.com 